\title{
da
}

DA, n², enero-diciembre 2015, ISSN: 1989-8983

\section{LA POTESTAD SANCIONADORA DE LA ADMINISTRACIÓN Y VUELTA A LA CASILLA DE SALIDA}

\author{
Miguel Casino Rubio \\ Universidad Carlos III de Madrid \\ mcasino@der-pu.uc3m.es
}

\begin{abstract}
El proyecto de Ley de Régimen Jurídico del Sector Público (en adelante LRJSP) dedica el Capítulo III de su Título Preliminar a los «principios de la potestad sancionadora». A vista de pájaro y, desde luego, a medida que se desciende al texto se ve enseguida que la reforma se ha quedado corta y, en cualquier caso, muy lejos de la reclamación doctrinal que desde hace tiempo defiende la oportunidad de que el legislador ofrezca una referencia conceptual única que, al tiempo que sirva de guía o de eje vertebrador para los abundantes regímenes jurídicos sancionadores hoy dispersos por el ordenamiento, con soluciones no siempre coincidentes, subraye la propia identidad y autonomía del Derecho administrativo sancionador frente al Derecho penal (por todos, aunque con apreciables matices entre las respectivas opiniones, REBOLLO PUIG, 2003; HUERGO LORA, 2007; CANO CAMPOS, 2011; NIETO, 2012; y PAREJO ALFONSO, 2014).
\end{abstract}

Para hacerlo, de hecho, bastaba con mirar al Derecho comparado o, sin salir de nuestras fronteras, con fijarse en la Ley 2/1998, de 20 de febrero, de la Potestad sancionadora de las Administraciones públicas del País Vasco'. De todas formas, y si no quería llegar tan lejos, el legislador general debería al menos haber echado una ojeada a su alrededor y visto el panorama de las soluciones ideadas por el legislador sectorial y lo principal de la jurisprudencia (tanto constitucional como ordinaria), y de la doctrina científica de los últimos veinte años, y haber aprovechado alguna de sus múltiples enseñanzas.

Imágenes visuales aparte, nada de todo esto ha hecho sin embargo el moderno legislador que, siguiendo ad pedem leterem el mismo esquema de la LRJPAC, apenas incorpora unas pocas novedades de interés. Una debilidad que está reconocida incluso por el propio legislador cuando en la Exposición de Motivos del citado Proyecto, tan propensa a la celebración de las novedades, no destaca sin embargo ninguna en materia sancionadora, seguramente porque con honestidad no encuentra ningún motivo para hacerlo.

No es mucho mejor el juicio que por su parte merece el Proyecto de Ley del Procedimiento administrativo común de las Administraciones públicas (en adelante LPAC), que tampoco contiene, con la salvedad que luego veremos, ninguna novedad realmente significativa entre todas las reglas que están desperdigadas a lo largo y ancho del procedimiento común que diseña.

De modo que, al final, el legislador deja las cosas prácticamente en el mismo punto en el que estaban. 0 incluso peor, porque ha desperdiciado una nueva oportunidad para atar algo mejor alguno de los muchos cabos que desafortunadamente todavía andan sueltos en este asunto de la potestad sancionadora de la Administración. Algo así, en fin, como que los veintidós años largos pasados desde la aprobación en 1992 de la LRJPAC, con todas sus discusiones doctrinales y jurisprudenciales, y las propias soluciones normativas ideadas por el legislador sectorial en todo este tiempo, no hubieran existido o nada importaran en rigor.

Sea como fuere, y matices aparte, se me ocurren ahora al menos media docena de observaciones. Son las que brevemente apunto a continuación, relativas las cuatro primeras a la LRJSP, y a la LPAC, las otras dos.

1 Sobre esta Ley vid., por todos, I. LAGASABASTER HERRARTE (dir.), La Ley de la Potestad Sancionadora. Comentario sistemático, LETE/ IVAP, Bilbao-Iruña, 2006. 


\section{i) La aplicación de los principios de la Ley a la potestad disciplinaria}

El art. 25.3 LRJSP establece que "las disposiciones de esta sección (sic) serán extensivas al ejercicio por las Administraciones públicas de su potestad disciplinaria respecto del personal a su servicio, cualquiera que sea la naturaleza jurídica de la relación de empleo".

Con esta declaración la Ley corrige el rumbo del vigente art. 127.2 LRJPAC y sujeta ahora la potestad disciplinaria de la Administración a los mismos principios que ordenan el ejercicio de su potestad sancionadora. Con la eliminación de la apuntada excepción el Proyecto suprime, pues, una de las previsiones de la LRJPAC que había sido más criticada por algunos autores, por apuntar tendencialmente a un círculo de inmunidad en las denominadas relaciones especiales de sujeción (NIETO, 1993,: 65 y ss.; MESTRE DELGADO, 1993: 375-376).

Al abrigo de esta excepción las Leyes de Función pública establecieron sus propias soluciones. Probablemente una de las más significadas, que cuenta además con el favor de la doctrina del Tribunal Constitucional² ${ }^{2}$ ha sido la de considerar que "la reserva de ley pierde parte de su fundamentación material en el seno de las relaciones de sujeción especial", de modo que en el caso de la potestad disciplinaria de la Administración el principio de legalidad funciona con algo menos de vigor.

Esta concepción rebajada del principio de legalidad es probablemente la que mejor explica que la jurisprudencia no haya formulado nunca ningún reparo por ese motivo contra el Reglamento del Régimen Disciplinario de los Funcionarios Públicos de la Administración del Estado, aprobado por Real Decreto 33/1986, de 10 de enero, a pesar de que buena parte de las infracciones que tipifica y, desde luego, todas las graves del art. 7.1, y sus correspondientes sanciones, no tiene icto oculi cobertura legal en ninguna de las previsiones del art. 31 de la Ley de la Reforma de la Función Pública de 1984 que formal y expresamente desarrolla3 ${ }^{3}$. Como tampoco enlazan fácilmente con lo dispuesto hoy en materia disciplinaria en el vigente Estatuto Básico del Empelado Público de 2007 (SÁNCHEZ MORON, 2013: 319), que tampoco tipifica las infracciones graves, confiando esa tarea al legislador futuro.

En este contexto, la opción del Proyecto por sujetar la potestad disciplinaria a los mismos principios que ordenan la potestad sancionadora, y que bien parece demasiado rigurosa, provoca además nuevos interrogantes.

Singularmente echa más leña al fuego que algún Tribunal ha encendido al notar que, con el art. 95.3 EBEP en la mano ${ }^{4}$, todas las infracciones disciplinarias graves que hoy tipifica el art. 7 del citado Reglamento de Régimen Disciplinario de 1986 carecen de la imprescindible cobertura legal y vulneran por este motivo el principio de legalidad del art. 25.1 CE.

Es el caso señaladamente, de la Sala del TSJ de Valencia que, en una jurisprudencia uniforme, que arranca de la Sentencia de 28 de julio de 2010, y a la que luego han seguido simplemente otras muchas ${ }^{5}$, ha concluido que,

“a partir de la entrada en vigor del EBEP, ha quedado derogada la tipificación y sanción de las infracciones graves realizada por el Reglamento de Régimen Disciplinario de los Funcionarios de la Administración del Estado (RD 33/86), al ser, por su condición jerárquica de norma meramente reglamentaria, abierta y frontalmente incompatible con las exigencias de reserva de Ley en materia disciplinaria que se imponen por el citado EBEP, por lo que resulta directamente afectado por la derogación general prevista en la letra g) de su Disposición derogatoria única, y a falta de disposiciones de Derecho Transitorio, se ha generado un vacío normativo con relación a la tipificación y sanción de las faltas disciplinarias graves".

2 SSTC 2/1987, de 21 de enero; y 219/1989, de 21 de diciembre; y AATC 59/2004, de 24 de febrero; y 124/2005, de 4 de abril. Naturalmente la misma doctrina puede leerse en la jurisprudencia ordinaria. Sirvan de ejemplo, las SSTS de 21 de abril de 1998 ; de 11 de diciembre de 2000 y de 26 de abril de 2004 .

3 Vid, al respecto, B. MARINA JALVO, El régimen disciplinario de los funcionarios públicos, Lex Nova, $2^{\mathrm{a}}$ ed., Valladolid, 2001 , pp. 137 y ss.; T. QUINTANA LÓPEZ, "La potestad disciplinaria de las Administraciones sobre los empleados públicos", en el tomo II del doble número monográfico de Documentación Administrativa, coordinador por el propio autor, dedicado a La potestad sancionadora de las Administraciones públicas, números 282-283, 2009, en especial, pp. 328 y ss. J. M. TRAYTER JIMÉNEZ, “El régimen disciplinario de los funcionarios públicos en el EBEP”, en Comentarios al Estatuto Básico del Empleado Público, (Dir.: Salvador del Rey Guanter), La Ley/Wolters Kluwer, Madrid, 2008 , p. 911.

4 Las faltas graves serán establecidas por Ley de las Cortes Generales o de la Asamblea Legislativa de la correspondiente Comunidad Autónoma o por los convenios colectivos en el caso de personal laboral, atendiendo a las siguientes circunstancias: a) el grado en que se haya vulnerado la legalidad; b) la gravedad de los daños causados al interés público, patrimonio o bienes de la Administración o de los ciudadanos; y c) el descrédito para la imagen pública de la Administración".

5 Cfr., entre otras, sentencias de 14 de noviembre, de 3 de diciembre de 2014, y de 16 de enero de 2015. 
Frente a este razonamiento y la conclusión en que termina, realmente inquietante (SÁNCHEZ MORÓN, Ibidem), se alza, no obstante, otra línea jurisprudencial, defendida por la Sala de lo Contencioso-Administrativo de la Audiencia Nacional, que, siguiendo igualmente un criterio uniforme, afirma por su parte que esa tesis, además de desmontar por completo la potestad disciplinaria de las Administraciones públicas, no es técnicamente correcta. Literalmente porque, sin perjuicio del art. 95.3 EBEP,

"No por eso la potestad disciplinaria de la Administración del Estado, en cuanto a los funcionarios que dependen de dicha Administración General del Estado, ha quedado sin cobertura normativa, puesto que como dice el artículo 94 de la misma Ley, las Administraciones Públicas deben corregir disciplinariamente las infracciones del personal a su servicio de acuerdo con una serie de principios entre los cuales se encuentra el principio de legalidad y tipicidad de las faltas y sanciones, a través de la predeterminación normativa, o en el caso del personal laboral de los convenios colectivos. Indudablemente, dicho Reglamento disciplinario es un caso de predeterminación normativa hasta que se dicten las normas necesarias por las Cortes Generales [... ] y en todo caso, este mandato de dictar leyes de las Cortes Generales, está establecido en tiempo futuro o condicional: las leyes de función pública que se dicten en desarrollo del presente estatuto... [ ... ] En definitiva, el Estatuto Básico del Empleado Público no deja sin cobertura legal la potestad de la administración de corregir disciplinariamente a las personas sometidas en virtud de su relación funcionarial. [Por otra parte, además], la STC 219/1989, de 21 de diciembre, vuelve a reiterar que ese alcance de la reserva de ley pierde parte de su fundamentación en el seno de las relaciones especiales de sujeción"

Naturalmente, esta última conclusión pierde algo de pie y se debilita una vez que el legislador parece decidido elevar el listón del principio de legalidad en materia disciplinaria y desandar el camino andado hasta ahora ${ }^{6}$.

\section{ii) La definición de sanción administrativa}

Sobre el principio de tipicidad el art. 27 del Proyecto no añade ni una coma al vigente art. 129 LRJPAC, que ahora repite expressis verbis. Este silencio testimonia muy bien la falta de sensibilidad del legislador hacia la doctrina y jurisprudencia de los últimos veinte años, también ahora en un extremo fundamental: el concepto de sanción administrativa y sus tipos y límites.

Basta echar una ojeada a la jurisprudencia, tanto constitucional como ordinaria, para comprobar enseguida que hoy se cuentan por centenares las sentencias que se cuidan de distinguir las sanciones de otras medidas de intervención o policía administrativas de contenido igualmente desfavorable para su destinatario. Como conocidos son también los esfuerzos doctrinales (PEMÁN GAVÍN, 2000; CASINO RUBIO, 2000 y 2009; REBOLLO PUIG, 2001 y 2010; HUERGO LORA, 2007; y CANO CAMPOS, 2011), por perfilar mejor el concepto de «sanción administrativa» y ofrecer unos pocos criterios que permitan con mayor seguridad colocar en su lugar a la medida administrativa en cada caso considerada.

De todas formas, y aunque mucho se ha avanzado en este terreno, abundan no obstante también los supuestos de medidas administrativas de dudoso encaje, con interpretaciones radicalmente enfrentadas y soluciones normativas y jurisprudenciales para todos los gustos?.

En estas condiciones, el legislador bien podía haber echado una mano y contribuido de paso a despejar algunas dudas. Principalmente el Proyecto de Ley debería, al menos, haber fijado las características y límites de las sanciones, para de este modo,

a) Neutralizar el riesgo de su confusión con otras medidas de contenido desfavorable para su destinatario (revocación de actos favorables; pérdida de derechos; prohibiciones temporales), previstas en ocasiones

6 Naturalmente el problema está, como ha notado NIETO (Derecho Administrativo Sancionador, Tecnos, 5 ed., Madrid, 2012, pp. 208209 y 257), en afirmar simplemente, en contra y a pesar de las abundantes matizaciones que irremediablemente acaba imponiendo el sinnúmero y variedad de infracciones administrativas, que el principio de legalidad en materia sancionadora, que tiene su corolario en la reserva de ley, es de rango constitucional (art. 25.1 CE) y, por tanto, indisponible para el legislador ordinario.

7 Valga como ejemplo el caso de la retirada del carné de conducir por la pérdida total del saldo de puntos disponible. Sobre esta cuestión vid., M. CASINO RUBIO, “La disputada naturaleza jurídica de la declaración de pérdida de vigencia del permiso de conducción por extinción del saldo de puntos”, en Las sanciones de tráfico, monográfico de la Revista Documentación Administrativa coordinado por el propio autor citado, núm. 284-285, 2009, pp. 253 y ss. En contra, T. CANO CAMPOS, Las sanciones de tráfico, Aranzadi/Thomson Reuters, Cizur Menor (Navarra), 2011, pp. 331 y ss. A medio camino entre ambas posiciones, A. HUERGO LORA, Las sanciones administrativas, cit. pp. 339 por nota y 344 . 
como medidas accesorias, y que en mi opinión nada tienen que ver en rigor con la idea de sanción administrativa ${ }^{8}$.

b) Salir al paso del riesgo de ver en la sanción administrativa una medida alternativa a la respuesta penal, simplemente rebajada en grado, y, por tanto, intercambiable con la pena siguiendo el compás de los procesos de despenalización de los ilícitos que marca el legislador ${ }^{9}$.

Muy lejos de este propósito, el art. 272 del Proyecto se contenta con recordar sumariamente, siguiendo el criterio de la LRJPAC, que las sanciones "en todo caso estarán delimitadas por la ley"10.

8 La revocación de actos favorables (licencias y autorizaciones, prestaciones públicas e inscripciones) es seguramente uno de los asuntos más controvertidos, con opiniones jurisprudenciales y doctrinales también para todos los gustos. Esta dificultad está reconocida por el propio Tribunal Constitucional, según lo certifica la STC 181/1990, de 15 de noviembre, cuando abiertamente reconoce que la distinción entre la simple revocación y la revocación-sanción no es una tarea nada sencilla. Pero no desde luego el único caso. Otro tanto vale para el recargo en las prestaciones de la Seguridad Social en los supuestos de accidente laboral como consecuencia del incumplimiento de las medidas de seguridad en el trabajo, o, en fin, para las prohibiciones temporales para, por ejemplo, obtener subvenciones, entrar en territorio español o, en fin, ser nombrado alto cargo, que respectivamente establecen las Leyes general de subvenciones, de extranjería, y de transparencia, acceso a la información pública y buen gobierno. Estas últimas prohibiciones, que las respectivas leyes citada tipifican efectivamente como sanciones, en algún caso con el aval expreso del propio Tribunal Constitucional (Cfr. STC 17/2013, de 31 de enero; FJ 12), me parecen, efecto, que nada tienen que ver con la idea de sanción administrativa y testimonian el derroche sancionador del Legislador y, al cabo, su desorientación. Aunque probar este extremo me llevaría ahora muy lejos baste notar en este momento que parecidas medidas funcionan en nuestro ordenamiento administrativo descargadas de todo componente sancionador. Es el caso, entre otras, de la pérdida del requisito de la honorabilidad que contempla el art. 44 de la Ley 16/1987, de ordenación de los transportes terrestres, o de la pérdida igualmente de la posibilidad de participar en los procesos selectivos para el acceso al empleo público del art. 56 EBEP. Vid., al respecto, A. HUERGO LORA, Las sanciones administrativas, cit., pp. 332 y ss. También, para una visión general, REBOLLO PUIG, Derecho Administrativo Sancionador, (junto con M. IZQUIERDO CARRASCO, L. ALARCÓN SOTOMAYOR y A. Ma BUENO ARMIJO) Lex Nova, Valladolid, 2010, pp. 67 y ss.

Sobre todo esto resulta muy ilustrativa la consulta del art. 143.5 de la citada Ley 16/1987, de transportes terrestres, y de la STC 5/2004, de 16 de enero, (asunto: ilegalización del partido político Batasuna), en la medida que proporcionan a mi juicio una buena pista sobre el camino correcto a recorrer en este tipo de asuntos, saliendo al paso del riesgo de ver en ese tipo de explicaciones (sobre el significado no sancionador de la comprobación de la desaparición o el incumplimiento a posteriori de los requisitos legales necesarios), un simple ardid con el que enredar las cosas y rebajar de contenido sancionador a ese tipo de revocaciones. Esta observación alerta sobre la posibilidad de que por esa vía, esto es, mediante el simple expediente de incorporar el correspondiente régimen sancionador (rectius: el cuadro de infracciones) a la nómina de requisitos necesarios para el otorgamiento de la preceptiva autorización, se acabe metiendo todo el Derecho administrativo sancionador en el saco de las revocaciones por desaparición sobrevenida de las condiciones y neutralizando, de paso, todo el arsenal de garantías vinculadas al ius puniendi. Aunque reconozco el peso de esta objeción, la misma me parece en cualquier caso que se fija demasiado en las garantías del infractor y, por tanto, que sigue sin mirar a la protección de los intereses generales a los que sirve la Administración.

9 Las recientes Leyes Orgánicas 1/2015, de modificación del Código Penal de 1995, y 4/2015, de Protección de la Seguridad Ciudadana, ambas de 30 de marzo, son seguramente el mejor ejemplo, en la medida que testimonian muy bien el apuntado riesgo de utilización del Derecho sancionador como instrumento de política criminal, sin sujeción a ningún criterio teórico, salvo el de la menor gravedad de la sanción administrativa. Naturalmente esta confusión toma pie en la idea, hoy dominante, de la unidad del ius puniendi del Estado, que puede manifestarse alternativamente sin solución de continuidad en forma de pena o sanción administrativa. En este contexto no pueden extrañar las voces que con razón alertan sobre el preocupante fenómeno de la «administrativización» del Derecho penal y de la «penalización» del Derecho administrativo. Cfr., al respecto, entre otros, J. Ma SILVA SÁNCHEZ, La expansión del derecho penal. Aspectos de política criminal en las sociedades postindustriales, Civitas, $1^{\text {a }}$ ed., Madrid, 1999; S. MUÑOZ MACHADO, Tratado de Derecho Administrativo y Derecho Público General, I, $3^{\text {a }}$ ed., lustel, Madrid, 2011, pp. 82 y ss.; L. PAREJO ALFONSO, “La deriva de las relaciones entre los Derechos administrativo y penal. Algunas reflexiones sobre la necesaria recuperación de su lógica sistémica”; en Documentación Administrativa, núm. 284-285, 2009, pp. 273 y ss.; y J. A. GARCíA AMADO, "Sobre el ius puniendi: su fundamento, sus manifestaciones y sus límites", en Documentación Administrativa, núm. 280-281, 2008, pp. 11 y sS.

10 A poco que se observe podrá verse en esta prescripción una diferencia fundamental respecto del mandado de tipificación de las infracciones. Pues, mientras que en materia de infracciones el LRJSP subraya el carácter rigurosamente formal de la correspondiente definición legal, de modo que "solo constituyen infracciones administrativas las vulneraciones del ordenamiento previstas como tales infracciones por una Ley” (art. 27.1), al hablar de las sanciones rebaja el protagonismo del legislador y se conforma, en efecto, con advertir simplemente que deberán estar "delimitadas por la ley". Esta declaración del Proyecto entronca directamente con la concepción material y no meramente formal del concepto de sanción administrativa que desde hace tiempo, a impulsos del Tribunal Constitucional (que arrancan de la decisiva STC 239/1988, de 14 de diciembre), es dominante entre nosotros (HUERGO LORA, 2007: 188 y ss.; REBOLLO PUIG, 2010: 59-61), con muy contadas excepciones (PEMÁN GAVÍN, 2000: 97-98). Resumiendo ahora las cosas, según esa concepción material, la naturaleza sancionadora de una determinada medida administrativa no depende de la calificación formal que, a su discreción, haya decidido otorgarle la Administración o, ya antes, la Ley, sino de su verdadero contenido y finalidad.

La defensa de la concepción material de sanción administrativa tiene desde luego innegables ventajas. Sirve para neutralizar las manipulaciones de la institución, conscientes o no, esto ahora no importa tanto, y permite ajustar mejor el Ordenamiento, aproximando la sustancia a la forma. Pero tiene también algún inconveniente. El principal es que una vez que se ha empezado a rodar por esa pendiente es ya muy difícil detener la caída y, en consecuencia, cuando la opinión del Legislador o de la Administración no es ya la que verdaderamente importa, muchas de las medidas administrativas se convierten en sospechosas y quedan sometidas al escrutinio y decisión de los Jueces y Tribunales. Y ni que decir tiene que cuando esto sucede, cuando la depuración del concepto se hace a golpe de resolución judicial, sin pautas técnicas que sirvan de guía, la consistencia de las soluciones y la seguridad jurídica acaban pagando irremediablemente la factura. Algo que de todas formas que acaso sea inevitable, sobre todo para quienes defienden la concepción material de sanción administrativa, pero que hay que tener bien presente en todo caso, porque, como es fácil de comprobar, soluciones normativas y sentencias las hay, en efecto, prácticamente para todos los gustos. 


\section{iii) La graduación de las infracciones en vía administrativa}

Idéntica o parecida despreocupación por el contexto legislativo y por las explicaciones doctrinales y jurisprudenciales de los últimos casi veinticinco años, es la que despunta igualmente en el art. 27.3 del proyecto cuando, siguiendo la fórmula del art. 129.3 de la LRJPAC, declara que "las disposiciones reglamentarias de desarrollo podrán introducir especificaciones o graduaciones al cuadro de las infracciones o sanciones establecidas legalmente que, sin constituir nuevas infracciones o sanciones, ni alterar la naturaleza o límites de las que la Ley contempla, contribuyan a la más correcta identificación de las conductas o a la más precisa determinación de las sanciones correspondientes".

Sobre el grado de precisión o tipificación exigible a la Ley hay bastante escrito y existe también ya una consolidada doctrina constitucional que permite marcar con relativa seguridad el campo de colaboración del Reglamento en la tipificación de infracciones y sanciones. Mucho menos se ha dicho, sin embargo, sobre la posibilidad, que contemplan no pocas leyes sectoriales"1, de que la ley descargue en la Administración la operación de determinar por sí misma la gravedad del ilícito, calificando la infracción previamente tipificada por la ley como leve, grave o muy grave en función de los criterios que la propia ley se encarga también de precisar (comúnmente cifrados en la repercusión de la infracción en la integridad de personas y bienes, en el grado de culpa o reincidencia, en la posición del infractor, y en la cuantía del beneficio obtenido).

Sé muy bien que el propio Tribunal Constitucional ha terciado en este asunto (SSTC 100/2003, de 2 de junio; 210/2005, de 18 de julio; 98/2006, de 27 de marzo; 187/2006, de 19 de junio; y 252/2006, de 25 de julio; 166/2012, de 1 de octubre; y 10/2015, de 2 de febrero) y dejado claro que "[cuando] el precepto cuestionado traslada la calificación de las infracciones a un momento aplicativo posterior y, por ende, externo a la previsión legal, [lo hace] en contra de la vertiente material del derecho a la legalidad sancionadora recogido en el art. 25.1 CE" (FJ 5). Lo que significa, como está dicho en esa misma jurisprudencia, que "[la] calificación ad hoc de las infracciones no resulta acorde con el principio de taxatividad en cuanto que no garantiza mínimamente la seguridad jurídica de los ciudadanos, quienes ignoran las consecuencias que han de seguirse de la realización de una conducta genéricamente tipificada como infracción administrativa".

Si apuramos ahora estas declaraciones constitucionales una conclusión salta inmediatamente a la vista. Hasta la fecha, el Tribunal Constitucional ha observado la exigencia de tipificación o de predeterminación normativa de las infracciones con notable mayor severidad que la que utiliza cuando ha examinado esa misma exigencia en relación con las sanciones, como lo certifica la naturalidad con la que ha admitido siempre que la Administración pueda determinar de cada vez la concreta sanción a imponer, dentro de los límites señalados en la propia Ley, normalmente mediante la utilización de una horquilla, y con arreglo a los criterios de graduación que la misma Ley asimismo acostumbra a precisar ${ }^{12}$.

Esta forma de tipificar las sanciones es absolutamente frecuente y, de hecho, son contadas las leyes sancionadoras que fijan con precisión la sanción que automáticamente corresponde a cada una de las infracciones que tipifica. De hecho, no faltan tampoco, las que habilitan a la Administración, no ya para que, como es más habitual, determine el quantum o el alcance de la concreta sanción a imponer en cada caso con sujeción a los límites y criterios que previamente ha fijado la misma ley, sino para que seleccione entre los tipos de sanciones legalmente previstas la que mejor conviene para corregir la infracción cometida, incluso de forma acumulada ${ }^{13}$.

Con estos presupuestos es lógico preguntarse por qué una habilitación legal de este tipo en favor de la Administración (la remisión a un momento aplicativo posterior, por seguir la expresión de la citada STC 100/2003, a la

11 Este es, en efecto, el esquema que siguen por ejemplo el art. 39.1 de la Ley 4/1989, de 27 de marzo, de conservación de los espacios naturales y de la flora y fauna silvestres; el art. 30 de la Ley del Parlamento de Cataluña 3/1993, de 5 de marzo, del Estatuto del Consumidor; o, en fin, y más modernamente también del art. 50.1 del Texto Refundido de la Ley General para la Defensa de los Consumidores y Usuarios, aprobado por Real Decreto Legislativo 1/2007, de 16 de noviembre.

12 En efecto, según es doctrina constitucional consolidada, "resulta compatible con la garantía del principio de legalidad sancionadora que el legislador atribuya discrecionalidad a la Administración dentro de unos límites para concretar el alcance o importe de la sanción” (por todas, STC 175/2012, de 15 de octubre, FJ 3).

13 Entre otros preceptos, el art. 89.1 de la Ley 8/1990 de Caza de Extremadura; el art. 67.2 del texto articulado de la Ley de Tráfico, aprobado por Real Decreto Legislativo 339/1990, de 2 de marzo; y, por último, el art. 57.1 de la Ley Orgánica 8/2000, de 22 de diciembre, sobre derechos y libertades de los extranjeros en España, acreditan, en efecto, la existencia de ese tipo de remisiones legales en favor de la Administración. El citado art. 89.1 de la Ley extremeña de caza advertía que las infracciones leves "serán sancionadas con multa [... ], pudiendo llevar implícita la retirada de la licencia [de caza] o la imposibilidad de obtenerla por un plazo de 1 a 2 años”. Por su parte el art. 67.2 de la Ley de Tráfico precisa para el caso de la infracción muy grave del art. 65.6 e), relativa a las autoescuelas, que, además de la correspondiente multa, "se podrá imponer la sanción de suspensión de la correspondiente autorización por el periodo de un año”. Finalmente, el art. 57.1 de la Ley de Extranjería establece que para corregir las infracciones muy graves y determinadas infracciones graves que el propio precepto identifica, "podrá aplicarse, en atención al principio de proporcionalidad, en lugar de la sanción de multa, la expulsión del territorio español, previa la tramitación del correspondiente expediente administrativo y mediante resolución motivada que valore los hechos que configuran la infracción". 
que luego han seguido todas las demás) es constitucionalmente legítima cuando se trata de graduar sanciones y no lo es, en cambio, cuando se trata de graduar infracciones. O si prefiere, cuál es la razón que justifica esa distinta vara de medir.

Dejo ahora el interrogante nada más que planteado, aunque adelanto ya mi opinión contraria. En todo caso, me parece, en efecto, que esa es una pregunta que es muy difícil de esquivar y que tiene una apariencia algo inquietante y que deja en mal lugar a la doctrina constitucional. Sobre todo si, como tampoco es infrecuente que suceda en la realidad, la ley utiliza los mismos criterios para uno y otro caso ${ }^{14}$.

Pero también si se tiene en cuenta que cuando lo que está en juego no es la tipificación o la predeterminación normativa de las conductas infractoras (dimensión o vertiente del principio de tipicidad que queda asegurada cuando la ley tipifica por sí misma las conductas ilícitas), sino únicamente la calificación de esas infracciones en alguna de las categorías de leve, grave o muy grave, lo que de verdad se arriesga (aunque no solo), es la determinación de la sanción a imponer por la infracción cometida, puesto que a medida que se asciende en la escala de calificación de la infracción se agrava también la sanción que le corresponde.

De modo que, apurando este planteamiento, la imprevisibilidad o inseguridad jurídica que plantea esta forma de tipificación de las infracciones se resume, a fin de cuentas, en un problema asimismo de relativa inseguridad sobre la sanción que finalmente ha de corresponder a la infracción cometida. En consecuencia, en este tipo de asuntos la imprecisión está principalmente en la consecuencia jurídica, no en el supuesto de hecho de la norma y, por tanto, apunta directamente a la tipicidad de las sanciones, no de las infracciones.

\section{iv) La culpabilidad y la exigencia de dolo o culpa}

El asunto de la culpabilidad en el Derecho administrativo sancionador es seguramente una de las cuestiones más confusas (NIETO, 2012: 572) y que más comentarios han suscitado, en efecto (PEMAN GAVíN, 2000: 292). El art. 28.1 del Proyecto precisa ahora que sólo podrán ser sancionados quienes resulten responsables de las mismas "a título de dolo o culpa" y no, por tanto, a título de simple inobservancia, como hoy declara el vigente art. 130.1 LRJPAC.

Hay naturalmente en esta declaración del Proyecto una apuesta decidida por el elemento subjetivo de la culpabilidad en la exigencia de responsabilidad por los hechos típicos o, por decirlo negativamente, por cerrar la puerta a cualquier idea de responsabilidad objetiva o sin culpa, o justificada en el mero incumplimiento de las normas, y que con algo de alarma para algunos dejó abierta la regla de la simple inobservancia (CHINCHILLA MARÍN, 1993: 761; y DE PALMA, 1996: 134 y ss.) $)^{15}$.

Esta opción del Proyecto me parece, sin embargo, algo precipitada. Primero, porque su aplicación solo ha de servir para generar nuevos problemas interpretativos, supuesto que la exigencia de dolo o culpa no casa fácilmente y deja en mal lugar a las abundantes leyes administrativas que usan el criterio de la simple inobservancia y a la larga lista de infracciones formales que esas mismas leyes establecen (que no necesitan de dolo o culpa ni producir ningún resultado lesivo). Y segundo, porque esa regla, que presupone la idea de un único ius puniendi, echa tierra nuevamente sobre la necesaria autonomía del Derecho administrativo sancionador, con riesgo de dinamitar la gestión administrativa en amplios sectores vinculados al control y supervisión administrativos de actividades de riesgo, y que no necesitan para funcionar probar la existencia de la lesión o la puesta en peligro de ningún bien jurídico (sanidad animal, seguridad alimentaria, tráfico, artículos pirotécnicos...).

Singularmente no tiene en cuenta que mientras el Derecho penal es un derecho retributivo, el Derecho administrativo sancionador es de corte preventivo (NIETO, 2012: passim) de modo que la sanción, a diferencia de la pena, no persigue retribuir la infracción, sino simplemente corregir la correspondiente conducta para evitar que

14 Lo certifica ejemplarmente el art. 39.4 de la propia Ley 4/1989, de 27 de marzo, de conservación de los espacios naturales y de la flora y fauna silvestres, cuando expresamente advierte que "los criterios establecidos en el primer apartado de este artículo [para calificar la correspondiente infracción de leve, grave o muy grave] se tendrán en cuenta para graduar la sanción que se imponga dentro del intervalo correspondiente a cada infracción".

15 De hecho, para intentar salvar la vigencia del principio de culpabilidad, del que no es fácil desprenderse, la doctrina ha ofrecido diversas explicaciones, ya para incluir la simple inobservancia en la imprudencia (LAZCANO BROTONS, 2006: 108), concebirla como equivalente a la falta levísima (DE PALMA, 1996: 135-137), o considerarla incluida en el incumplimiento de la diligencia debida (HUERGO LORA, 2007: 388) o de la correspondiente norma de cuidado incorporada al propio tipo infractor (CANO CAMPOS, 2011: 210). Todas estas explicaciones son desde luego respetables y tienen, además, el mérito de que permiten cumplir constitucionalmente con la exigencia sin fisuras del principio de culpabilidad. Pero alertan también de las complicaciones de intentar salvar un dogma que acaso no merece ser conservado (NIETO, 212:348) y que tiene uno de sus test más difíciles en las denominadas "infracciones formales" o de "mera desobediencia”, y que no necesitan de dolo o culpa ni producir ningún resultado lesivo. De modo que en este tipo de asuntos es el incumplimiento o la desobediencia, y no el resultado, lo que verdaderamente parece importar. 
se cometan nuevas infracciones, favoreciendo de este modo la efectividad del fin colectivo perseguido por la correspondiente acción administrativa.

Por decirlo en otros términos, mientras en el Derecho penal el Juez castiga porque se ha lesionado un bien (punitur quia peccatum est) capaz de justificar la restricción de la libertad personal, y se caracteriza en consecuencia por la antijuridicidad material (PAREJO ALFONSO, 2013: 18.), de manera que el delito es finalmente la medida y el fundamento de la pena correspondiente, en el Derecho sancionador la Administración castiga para que no se perturbe el interés público o colectivo (punitur, ut ne peccetur), de forma que la infracción no es la causa y medida de la sanción, sino la ocasión para que la Administración corrija el comportamiento desviado con fines preventivos, buscando que la correspondiente norma se cumpla (NIETO, 2012: 103-104). De ahí precisamente el principio de oportunidad que es característico del ejercicio de la potestad sancionadora ${ }^{16}$, y la posibilidad de su utilización también como alternativa o complemento a las técnicas positivas de fomento de la consecución de ese mismo interés general.

Naturalmente todas estas observaciones no significan, sin embargo, que el Derecho sancionador administrativo deba abandonar la idea o la teoría de culpabilidad. Alertan simplemente de la necesidad de calibrar muy bien la exigencia de responsabilidad culpable, so pena de arrinconar a las abundantes normas ideadas en materia de prevención de riesgos abstractos y a la larga lista de infracciones puramente formales que no necesitan de dolo o culpa ni producir ningún resultado lesivo, y que están salpicadas por todo el ordenamiento.

\section{v) El programa de clemencia}

El art. 62.3 del Proyecto del Procedimiento administrativo incorpora, como anunciaba al principio, una novedad realmente llamativa cuando, al hilo de la incoación del procedimiento por denuncia ${ }^{17}$, establece que,

“en todo caso, cuando el denunciante haya participado en la comisión de una infracción de esta naturaleza y existan otros infractores, el órgano competente para resolver el procedimiento deberá eximir al denunciante del pago de la multa que le correspondería u otro tipo de sanción de carácter no pecuniario, cuando sea el primero en aportar elementos de prueba que permitan iniciar el procedimiento o comprobar la infracción, siempre y cuando en el momento de aportarse aquellos no se disponga de elementos suficientes para ordenar la misma y se repare el perjuicio causado."

Asimismo, el órgano competente para resolver deberá reducir el importe del pago de la multa que le correspondería o, en su caso, la sanción de carácter no pecuniario, cuando no cumpliéndose alguna de las condiciones anteriores, el denunciante facilite elementos de prueba que aporten un valor añadido significativo respecto de aquellos de los que se disponga.

En ambos casos será necesario que el denunciante cese en la participación de la infracción y no haya destruido elementos de prueba relacionados con el objeto de la denuncia.

Estas reglas, que están tomadas del Derecho penal y recuerdan mucho al denominado "programa de clemencia" que idearon los arts. 65 y 66 de la Ley 15/2007, de 3 de julio, de Defensa de la Competencia, y que desarrollaron luego los arts. 46 a 53 de su Reglamento (aprobado por RD 261/2008, de 22 de febrero), y que más tarde, con matices, ha incorporado también el art. 59 de la Ley Orgánica 4/2000, de 11 de enero, de derechos y libertadas de los extranjeros en España, (en su versión modificada por la Ley Orgánica 2/2009, de 11 de diciembre), como medio para luchar contra las redes organizadas de tráfico y explotación de seres humanos, son bastante discutibles, sin embargo.

Principalmente porque, a diferencia del programa de clemencia, que tiene muy concretado su ámbito, a la lucha contra los cárteles económicos, y que está pensado como fórmula con la que contrarrestar la dificultad de probar la existencia de este tipo de acuerdos (supuesto su carácter secreto y, por tanto, el hecho de que sus

16 El principio de oportunidad o la discrecionalidad en el ejercicio de la potestad sancionadora es asimismo una cuestión controvertida, con opiniones igualmente divididas. Vid., al respecto, B. LOZANO CUTANDA, “El principio de oficialidad de la acción sancionadora administrativa” RAP, núm. 161, 2003, pp. 83 y ss.; A. NIETO, Derecho Administrativo Sancionador, cit., pp. 100 y ss. E. DESDENTADO DAROCA, “Discrecionalidad administrativa en la imposición de sanciones", en Diccionario de sanciones administrativas (dir., B. LOZANO CUTANDA, lustel, Madrid, 2010, pp. 340 y ss.; REBOLLO PUIG, Derecho Administrativo Sancionador, cit., pp. 473 y ss. ; y M. GÓMEZ TOMILLO-I. SANZ RUBIALES, Derecho Administrativo Sancionador. Parte General, Thomson Reuters-Aranzadi, Cizur Menor, 2013, pp. 725 y ss. Este principio está plenamente reconocido en el Derecho alemán, según testimonia A. HUERGO LORA, Las sanciones administrativas, cit., pp. 69 y ss.

17 Sobre la denuncia y, en particular, el papel, siempre polémico, del denunciante en el procedimiento sancionador, por todos, E. COBREROS MENDADOZA, “El reconocimiento al denunciante de la condición de interesado”, en El Derecho en el umbral del siglo XXI. Homenaje al profesor Ramón Martín Mateo, Tiran lo Blanch, tomo II, Valencia, 2000, pp. 1437 y ss. Más recientemente vid. G. DOMENECH PASCUAL, "Roma delatoribus praemiat. La denuncia en el Derecho Público”, en Función Inspectora, Actas del VIII Congreso de la Asociación Española de Profesores de Derecho Administrativo (AEPDA), coord., J. J. DÍEZ SÁNCHEZ, INAP, Madrid, 2013, pp. 171 y ss. 
participantes se cuiden muy mucho de dejar huellas) y, en consecuencia, para garantizar la efectividad misma de las normas de competencia ${ }^{18}$, la aplicación indiscriminada de la citada regla legal a cualesquiera infracciones, sin ninguna matización o precisión añadida, y con el único límite de que sean infracciones no finalizadas (continuadas o permanentes ${ }^{19}$ ), solo puede servir para despertar los deseos justicieros de los ciudadanos o, lo que es probablemente peor, para fomentar la hostilidad entre vecinos, amigos o incluso familiares, que pueden ver en esa previsión una magnífica oportunidad para dar rienda suelta a sus deseos de venganza y a sus más bajas pasiones.

Y alerta en todo caso sobre una pretensión que es irreal, por imposible de alcanzar: el descubrimiento y el castigo de todos los ilícitos administrativos que diariamente se cometen. Una pretensión, además, que no casa tampoco muy bien con el principio de oportunidad que, según antes se ha observado, es característico del Derecho administrativo sancionador frente al Derecho penal ${ }^{20}$, y que, por tanto, apunta a negar una vez más su imprescindible autonomía.

\section{vi) la prueba de los hechos y la vinculación de la Administración a los hechos declarados probados por el Juez penal}

En materia de prueba son también muchos los extremos que han quedado pendientes. Y los hay también, entre los que en nada cambian, que reclamaban alguna precisión, y que el Proyecto evita nuevamente.

Es el caso, en primer lugar, de la regla, ciertamente ya clásica, que previene el art. 77.4 del Proyecto de Ley del Procedimiento Administrativo común cuando declara, siguiendo el criterio del vigente art. 137.3 LRJPAC, que "los hechos declarados probados por resoluciones judiciales penales firmes vincularán a las Administraciones públicas en los procedimientos sancionadores que sustancien".

Esta fórmula, según testimonian varios de sus principales comentaristas (SUAY, 1993: 389; NIETO, 2012: 460), parece que tomó forma a la vista de la contundente declaración que por entonces había hecho el Tribunal Constitucional cuando advirtió que, en los supuestos en los que unos mismos hechos arriesguen simultáneamente la comisión de un delito y de una infracción administrativa, el consiguiente doble enjuiciamiento, si posible en el plano jurídico, no alcanza, sin embargo "a la apreciación de los hechos, pues es claro que unos mismos hechos no pueden existir y dejar de existir para los órganos del Estado" (STC 77/1983, de 3 de octubre, FJ 4). De modo que, como precisará poco después el propio Tribunal, "en la realidad jurídica no puede admitirse que algo es y no es, que unos mismos hechos ocurrieron y no ocurrieron [... ], pues a ello se oponen no sólo principios elementales de la lógica jurídica y extrajurídica, sino el principio de seguridad jurídica constitucionalizado en el art. 9.3 CE" (STC 24/1984, de 23 de febrero, FJ 3$)^{21}$.

Esta declaración, que bien parece de puro sentido común, dista bastante sin de ser embargo de ser concluyente. Al menos por dos razones fundamentales.

Primero porque la declaración de hechos probados del Juez penal no equivale a la verdad material, sino que expresa simplemente el resultado probatorio del proceso. Pero nada más. De modo que no se advierte cuál es la razón epistemológica que impide que la Administración (o el Juez contencioso) pueda alcanzar una conclusión

18 Vid., entreotros,A.RAMOSGÓMEZyE.CABRERAMAQUEDA, “Elprogramaespañoldeclemencia, análisisycuestionesprácticas”,Gaceta Jurídica de la Unión Europea y de la Competencia, núm. 2, 2008, pp. 5 y ss.; L. BERENGUER FUSTER, "Reflexiones en torno al programa de clemencia”, Gaceta Jurídica de la Unión Europea y de la Competencia, núm. 28, 2012, pp. 11 y ss.; y P. PEREZ FERNÁNDEZ, "La problemática relación entre los programas de clemencia y las acciones privadas de resarcimiento de los daños derivados de ilícitos antitrust”, InDret, 1/2013.

19 STS de 4 de noviembre de 2013: "A diferencia de la infracción continuada que exige pluralidad de acciones que infrinjan el mismo precepto, y por ello constituye un concurso real de ilícitos, la infracción permanente no requiere un concurso de ilícitos, sino una única acción de carácter duradero, cuyo contenido antijurídico se prolongue a lo largo del tiempo, en tanto el sujeto activo no decida cesar en la ejecución de su conducta".

20 El art. 408 CP tipifica el delito de omisión del deber de perseguir delitos estableciendo que, "la autoridad o funcionario que, faltando a la obligación de su cargo, dejare intencionadamente de promover la persecución de los delitos de que tenga noticia o de sus responsables, incurrirá en la pena de inhabilitación especial para empleo o cargo público por tiempo de seis meses a dos años". Cfr., entre otras, las SSTS de 15 de marzo de 2012, y, mucho más recientemente, de 4 de febrero y 2 de junio de 2015 , que condenan a los respectivos funcionarios en cada caso imputados por no perseguir el correspondiente delito.

21 Importa notar, en cualquier caso, que la citada regla de vinculación tiene muy concretado su ámbito. Solo funciona respecto de los hechos expresa y efectivamente declarados probados por la sentencia penal; pero no, en cambio, en relación con los hechos no probados. Pues, como es elemental, ni jurídica ni lógicamente es lo mismo decir que un hecho (positivo o negativo) se produjo en la realidad, que afirmar que no está probado con arreglo al estándar probatorio aplicable, pero sin afirmarlo ni negarlo de modo expreso. Desde esta perspectiva, los enunciados fácticos ("x") admiten en consecuencia dos negaciones distintas: la del propio enunciado (está probado que no "x"), que afirma realmente la prueba de un hecho negativo; y la negación de la falta de demostración del enunciado (no está probado "x"), que nada dice en cambio sobre la existencia en la realidad del hecho considerado. Simplemente afirma la falta de elementos de juicio suficientes para considerar probada la verdad de un enunciado de hecho. 
distinta sobre los hechos controvertidos al verlos en otro proceso $\mathrm{O}^{22} . \mathrm{Y}$, segundo, porque el propio Tribunal Constitucional ha puesto en entredicho su declaración solemne que antes he recordado al advertir que cuando "existe una resolución firme dictada en un orden jurisdiccional, otros órganos judiciales que conozcan del mismo asunto deberán también asumir como como ciertos los hechos declarados como tales por la primera resolución, o justificar la distinta apreciación que hacen de los mismos"23.

Sin salir de la prueba de los hechos, y como una manifestación más de la mezcla entre los Derechos penal y administrativo sancionador, el Proyecto deja asimismo pendiente la cuestión de la posibilidad o no de utilizar en el expediente sancionador las pruebas obtenidas en un proceso penal en curso (el contenido de las conversaciones intervenidas judicialmente; o los documentos hallados en virtud de la oportuna diligencia judicial de entrada y registro domiciliarios). Esta es una cuestión bien se comprende ciertamente decisiva, y que algunas Leyes han puesto ya sobre la mesa al disponer que la Administración podrá solicitar del Juez instructor que le sean remitidas aquellas diligencias de instrucción practicadas y que sean necesarias para el ejercicio de la potestad sancionadora, y que, no obstante, ha sido censurada por la doctrina y jurisprudencia más atentas ${ }^{24}$. Finalmente y resumiendo ahora las cosas, razonando que la Administración no puede servirse de unas pruebas que nunca podría haber obtenido en el expediente sancionador, por no existir previsión legal que autorice, fuera de la investigación penal, la intervención telefónica o la entrada y el registro domiciliarios del infractor.

\section{BIBLIOGRAFÍA}

ÁLVAREZ VIZCAYA, M., "Garantía y límites de los derechos fundamentales de los deportistas: infracción penal vs infracción deportiva", en El dopaje en el deporte. Comentarios a la Ley Orgánica 3/2013, de 20 de junio, de protección de la salud del deportista y lucha contra el dopaje en la actividad deportiva, PALOMAR OLMEDA, A. (Director), Dykinson, Madrid, 2013.

BERENGUER FUSTER, L., "Reflexiones en torno al programa de clemencia”, Gaceta Jurídica de la Unión Europea y de la Competencia, núm. 28, 2012.

CANO CAMPOS, T., Las sanciones de tráfico, 2 ${ }^{\mathrm{a}}$ ed., Aranzadi-Thomson Reuters, Cizur Menor (Navarra), 2011.

22 Según ha sido notado por la filosofía jurídica la verdad declarada en el proceso judicial es, en efecto, una verdad simplemente "institucionalizada", y que, por lo mismo, no siempre ni forzosamente coincide con la verdad objetiva. De hecho, y descartada la posibilidad de alcanzar la verdad absoluta (identificada con una regla general universal), y de hacerlo también a cualquier precio, la racionalidad empírica en la fijación judicial de los hechos no ofrece, en efecto, certezas matemáticas, sino simplemente resultados probables medidos en términos de credibilidad y contados a partir del conjunto de elementos de juicio disponibles y la motivación de la decisión judicial. Estas notas, que testimonian la singularidad del procedimiento de fijación judicial de los hechos, alertan también de la fragilidad de su resultado. Pues, como es elemental, poner punto y final a la discusión de la verdad no convierte en verdadera la declaración judicial de los hechos, que muy bien pueden ser falsos, y que, por lo mismo, tampoco conviene sacralizar demasiado. En suma, declarar un hecho probado, antes que afirmar su carácter verdadero, refiere simplemente la existencia de elementos de juicio suficientes para poder considerar probado un determinado enunciado de hecho, que podrá ser, sin embargo, falso.

23 Cfr., SSTC 158/1985, de 26 de noviembre; 16/2008, de 31 de enero; y 21/2011, de 14 de marzo. De modo que como se cuida de precisar esa misma jurisprudencia constitucional, "no se trata, pues, de que una jurisdicción haya de aceptar siempre de forma mecánica los hechos declarados por otra jurisdicción, sino que una distinta apreciación de los hechos debe ser motivada y por ello cuando un órgano judicial vaya a dictar una resolución que pueda ser contradictoria con lo declarado por otra resolución judicial debe exponer las razones por las cuales, a pesar de las apariencias, tal contradicción no existe a su juicio". En suma, por tanto, “unos mismos hechos, cuando la determinación de los mismos exija una previa calificación jurídica, pueden ser apreciados de forma distinta en diferentes resoluciones judiciales sin incurrir por ello en ninguna vulneración constitucional, [siempre] que el órgano judicial que se aparta de la apreciación de los hechos efectuada anteriormente en otra resolución judicial expon[ga] de modo razonado los motivos por los que se aparta de aquella primera calificación".

24 Art. 33.5 de la Ley Orgánica 3/2013, de 20 de junio, de protección de la salud del deportista y lucha contra el dopaje establece que “la Agencia Española de Protección de la Salud en el Deporte podrá solicitar que le sean remitidas aquellas diligencias de instrucción practicadas que sean necesarias para la continuación de los procedimientos sancionadores. Dicha petición será resuelta por el Juez de instrucción, previa audiencia de los interesados, en el plazo de 20 días. En dicha audiencia los interesados podrán solicitar que sean también remitidos los documentos que les puedan beneficiar. La resolución del Juez será plenamente respetuosa con el principio de proporcionalidad, entregando a la Administración, mediante resolución motivada, únicamente las diligencias que la aplicación de tal principio autorice.

En el caso de que la causa penal ya no se encuentre en fase de instrucción la petición se dirigirá al órgano jurisdiccional que esté conociendo de las actuaciones respecto de las diligencias de instrucción o de las pruebas ya practicadas".

Del lado de la doctrina científica, cfr., por todos, ÁLVAREZ VIZCAYA, 2013: 639 y ss.). De la lado de la jurisprudencia, la sentencia del Juzgado Penal núm. 21 de Madrid, de 29 de abril de 2013, afirma por ejemplo que las pruebas obtenidas "para la averiguación de un presunto ilícito penal mediante una diligencia de entrada y registro autorizada por un Juez de instrucción, con lo que supone de injerencia en los derechos fundamentales del interesado, no ha de servir para ser tenida en cuenta para su empelo en un procedimiento sancionador en el ámbito del cual nunca podría podido autorizarse la injerencia". Ya antes, la STS (Sala Tercera), de 30 de abril de 2012, declaró que "las conversaciones telefónicas están amparadas por el art. 18.3 CE y, por tanto, una actuación de los poderes públicos, en concreto de ejercicio de su ius puniendi en el orden disciplinario, que utilice dichas conversaciones telefónicas como prueba en el expediente disciplinario vulneran directamente dicho derecho fundamental, pues ni está amparada por un precepto legal, ni responde a ninguno de los fines que la permiten [según el art. 579.2 LEcrim. Interpretado a la luz del art. 8.2 CEDH]". 
CASINO RUBIO, M.,

- "La indebida confusión entre confusión entre sanciones y otras medidas administrativas de policía", en Revista de Estudios de la Administración Local y Autonómica, núm. 283, 2000.

- "La disputada naturaleza naturaleza jurídica de la declaración de pérdida de vigencia del permiso de conducir por extinción del saldo de puntos", en Las sanciones de tráfico, monográfico de la Revista Documentación Administrativa, números 284-285, 2009.

CHINCHILLA MARÍAN, C., "Potestad sancionadora de las Administraciones públicas”, en Administraciones Públicas y Ciudadanos (Estudio sistemático de la Ley 39/1992, de régimen jurídico de las Administraciones públicas, y del procedimiento administrativo común), Praxis, 1993.

COBREROS MENDADOZA, E., "El reconocimiento al denunciante de la condición de interesado", en El Derecho en el umbral del siglo XXI. Homenaje al profesor Ramón Martín Mateo, Tiran lo Blanch, tomo II, Valencia, 2000.

DESDENTADO DAROCA, E., “Discrecionalidad administrativa en la imposición de sanciones”, en Diccionario de sanciones administrativas (dir., B. Lozano Cutanda), lustel, Madrid, 2010.

GÓMEZ TOMILLO, M.-SANZ RUBIALES, I., Derecho Administrativo Sancionador. Parte General, Thomson Reuters-Aranzadi, Cizur Menor, 2013.

DOMENECH PASCUAL, G., "Roma delatoribus praemiat. La denuncia en el Derecho Público", en Función Inspectora, Actas del VIII Congreso de la Asociación Española de Profesores de Derecho Administrativo (AEPDA), coord., J. J. DÍEZ SÁNCHEZ, INAP, Madrid, 2013.

HUERGO LORA, A., Las sanciones administrativas, lustel, Madrid, 2007.

LAZCANO BROTONS, I., "Culpabilidad”, en La Ley de la potestad sancionadora. Comentario sistemático (Dir. I. LAGASABASTER HERRARTE), LETE/IVAP, Bilbao-Iruña, 2006.

LOZANO CUTANDA, B., "El principio de oficialidad de la acción sancionadora administrativa” RAP, núm. 161, 2003.

MESTRE DELGADO, J., "Los principios de la potestad sancionadora”, en La nueva Ley de régimen jurídico de las Administraciones Públicas y del procedimiento administrativo común, LEGUINA VILLA, J., y SÁNCHEZ MORÓN, M. (Directores), Tecnos, Madrid, 1993.

MUÑOZ MACHADO, S., Tratado de Derecho Administrativo y Derecho Público General, I, $3^{\text {a }}$ ed., lustel, Madrid, 2011.

NIETO GARCíA, A.,

- "La potestad sancionadora y los casos de especial sujeción en la Ley de Régimen Jurídico de las Administraciones Públicas, en Estudios sobre la nueva Ley de régimen jurídico de las administraciones públicas y del procedimiento administrativo común. Seminario de Derecho local (Curso 92-93),Ayuntament de Barcelona, 1993.

- Derecho administrativo sancionador, $5^{\mathrm{a}}$ ed., Tecnos, Madrid, 2012.

PALMA DEL TESO, A. DE, El principio de culpabilidad en el Derecho administrativo sancionador, Tecnos, Madrid, 1996.

\section{PAREJO ALFONSO, L.,}

- "Algunas reflexiones sobre la necesidad de la depuración del status de la sanción administrativa", Revista General de Derecho Administrativo, núm. 36, 2014.

- La deriva de las relaciones entre los Derechos administrativo y penal. Algunas reflexiones sobre la necesaria recuperación de su lógica sistémica"; en Documentación Administrativa, núm. 284-285, 2009.

PEMÁN GAVÍN, I., El Sistema Sancionador Español. Hacia una teoría general de las infracciones y sanciones administrativas, Cedecs, Barcelona, 2000.

PÉREZ FERNÁNDEZ, P., "La problemática relación entre los programas de clemencia y las acciones privadas de resarcimiento de los daños derivados de ilícitos antitrust", InDret, 1/2013.

RAMOS GÓMEZ, A., y CABRERA MAQUEDA, E., “El programa español de clemencia, análisis y cuestiones prácticas”, Gaceta Jurídica de la Unión Europea y de la Competencia, núm. 2, 2008. 


\section{REBOLLO PUIG, M.,}

- “El contenido de las sanciones”, Justicia Administrativa, número extraordinario, 2001.

- "Propuesta de regulación general y básica de la inspección y de las infracciones y sanciones administrativas”, en AA.VV., Estudios para la reforma de la Administración pública, INAP, Madrid, 2004.

- Junto con M. YZQUIERDO CARRASCO, L. ALARCÓN SOTOMAYOR y A. Ma BUENO ARMIJO, Derecho Administrativo Sancionador, Lex Nova, Valladolid, 2010.

SÁNCHEZ MORÓN, M., Derecho de la función pública, 7 a ed., Tecnos, Madrid, 2013.

SUAY RINCÓN, J., “Los principios del procedimiento sancionador”, en La nueva Ley de régimen jurídico de las Administraciones Públicas y del procedimiento administrativo común, LEGUINA VILLA, J., y SÁNCHEZ MORÓN, M. (Directores), Tecnos, Madrid, 1993. 